\title{
Por um Conceito de Vivacidade
}

\section{To a Concept of Vivacity}

\section{Resumo:}

Neste trabalho procuramos elaborar um conceito de vivacidade do ser utilizando intuições teóricas encontradas na obra do filósofo Gilbert Simondon, articulando-o, ao final, com elementos da clínica psicanalítica de Donald Winnicott. A constituição deste conceito responde à necessidade de pensar uma clínica para os nossos dias, nos quais o plano de engendramento das sensações se configura como o próprio território ético e político em que se produzem formas do sentir e pensar, bem como formas de adoecer.

Palavras-chave: Vivacidade. Individuação. Topologia. Simondon. Winnicott.

\section{Abstract:}

In this paper we develop a concept of vivacity using theoretical insights mainly found in the works of the philosopher Gilbert Simondon, linking it with elements of the psychoanalytic clinic of Donald Winnicott, at the end. The constitution of this concept reflects the need to think a clinic for our day, in which the plan of engendering sensations configures itself as the ethical and political territory in which forms of feeling and thinking as well as forms of illness are produced.

Keywords: Vivacity. Individuation. Topology. Simondon. Winnicott.
ARAGON, Luis Eduardo Ponciano. Por um conceito de vivacidade. Informática na Educação: teoria \& prática, Porto Alegre, v. 15, n. 1, p. 147-157, jan./jun. 2012.

\section{Luis Eduardo Ponciano Aragon}

Pontifícia Universidade Católica de São Paulo

\section{Introdução}

0 sistema capitalista contemporâneo, associado irremediavelmente ao avanço tecnológico, produz transformações nas maneiras de sentir e perceber, incidindo hoje no próprio plano de formação das sensações, dos desejos e dos pensamentos. Este plano pode ser pensado como composto por superfícies ativas (em processo de individuação): corporal/incorporal, eu/outro, subjetivo/objetivo, formal/informe, singular/geral, as quais compõem um território privilegiado de ação dos poderes hoje, e da resistência a eles.

A obra de Gilbert Simondon nos permite percorrer os processos de individuação, os mesmos tendo a relação como momento ontogenéticamente anterior aos indivíduos ${ }^{1}$, sejam eles físicos, biológicos ou psicossociais. Estes processos são acompanhados pela idéia de topologia, ou seja, a espaciotemporalidade

1 Já na introdução de sua tese Simondon refere que: "seria possível considerar toda verdadeira relação como tendo estatuto de ser, e como se desenvolvendo no interior de uma nova individuação; a relação não surge entre dois termos que já seriam indivíduos; ela é um aspecto da ressonância interna de um sistema de individuação; faz parte de um estado de sistema." (grifo do autor) (SIMONDON, 1989, p. 18). As traduções constantes deste trabalho são traduções livres. 
dos regimes de distribuição do que é interior e do que é exterior, do que se afigura enquanto passado e do que se mantém enquanto potencial para futuras individuações.

Pretendemos utilizar estas duas ferramentas conceituais - processos de individuação e topologia -, bem como intuições clínicas do psicanalista Donald Winnicott, para conceber uma idéia de vivacidade e propor que é esta mesma vivacidade que é mobilizada nos processos atuais de subjetivação e adoecimento.

\section{Transformações que convocam o pensar}

Franco Berardi propõe que a sensibilidade seja hoje o campo de batalha político, definindo sensibilidade como "a capacidade de entender sinais que não são verbais, nem verbalizáveis" (BERARDI, 2011). É a faculdade de "discernir o indiscernível, aquilo que é demasiado sutil para ser digitalizado" (BERARDI, 2011), sensibilidade que se dá à nível epidérmico no entre dos seres humanos, sustentando as relações empáticas. A economia de mercado e a aceleração da infosfera são, segundo Berardi, atores desta batalha (BERARDI, 2010). O primeiro estimula a competição e o isolamento, o que leva a uma precarização das relações. Já o segundo diz respeito a uma intensificação do ritmo da exploração cognitiva, o que predispõe o desenvolvimento da sensação de solidão, pânico e depressão, produção de um esgotamento nervoso e um sofrimento psíquiCo (BERARDI, 2010). O entrelaçamento da tecnologia da comunicação e do trabalho com a economia de mercado produz transformações nos corpos e mentes não só individuais, mas dos próprios padrões coletivos de produção de corporeidades e de pensamentos. O rapaz que prefere pegar a bibliografia para seu trabalho de conclusão de curso na internet, tendo os livros a três passos de distância é um exemplo da complexidade do processo de individuação de novas formas de um corpo sensível, palco fundamental de tensões estético-políticas hoje. Para Berardi os "cognitariados" procuram um corpo, um "ritmo empático" frente a "des-empatia" generalizada (BERARDI, 2011).

Paul Virilio já observava em 1995 que:

[...]com o sedentário contemporâneo da grande metrópole, a contração no lugar não atinge apenas a área de deslocamento e de atividade produtora de outrora, ela atinge em primeiro lugar o corpo dessa pessoa válida sobreequipada de próteses interativas cujo modelo se tornou o inválido equipado para controlar o seu meio ambiente sem se deslocar fisicamente (VIRILIO, 2000, p. 60).

Estas mudanças produzem o que chamou de "poluição dromosférica", ou seja:

[...] aquela que atinge a vivacidade do sujeito e a mobilidade do objeto ao atrofiar o trajeto, a ponto de o tornar inútil. Invalidez maior, resultante simultaneamente da perda do aparelho locomotor do passageiro, do telespectador, e da terra firme, desse grande solo, terreno de aventura da identidade de estar no mundo (VIRILIO, 2000, p. 60).

Nesta "ecologia do tempo" (VIRILIO, 1991), vamos conhecendo o paradoxal "encontro à distância", no qual não apenas o trajeto é transformado pela tecnologia, mas que a própria saída é abolida, ecologia de uma "chegada generalizada" (VIRILIO, 1991), em que a passividade do telespectador vai sendo substituída pela atividade das ações à distância. O que era próximo vai se tornando distante e vice-versa, promovendo uma mutação da relação entre o corpo afetivo e o trabalho cognitivo de manipulação de signos, e uma mutação da experiência do tempo e da distribuição dos espaços, ambos envolvidos nos processos de individuação do sentir e perceber. 


\section{Por uma tecno-estética aquém da oposição homem/máquina}

Importa apontar que não pactuamos com nenhuma perspectiva catastrofista, por ventura implicada nas concepções acima. Também não consideramos a tecnologia como natureza destacada do homem - e desta forma passível de ser idolatrada ou demonizada -, mas como partícipe de uma reciprocidade relacional diferencial. Simondon sobre este ponto afirma que também a relação homem/máquina tem estatuto de ser, e que para conceber isto é preciso entender que:

[...] o homem seja um ser inacabado que a máquina completa, e a máquina um ser que encontra no homem sua unidade, sua finalidade, e sua ligação ao conjunto do mundo técnico; homem e máquina são mutuamente mediadores, pois a máquina possui em seus caracteres a integração à espacialidade e a capacidade de salvaguardar a informação através do tempo, enquanto que o homem, por suas faculdades de conhecimento e seu poder de ação, sabe integrar a máquina à um universo de símbolos que não é espaciotemporal, e no qual a máquina não poderia jamais estar integrada por si mesma. Entre estes dois seres assimétricos se estabelece uma relação graças à qual uma dupla participação se realiza (SIMONDON, 1989, p.278).

Trata-se de um sistema ontogenético que é explicitado por Simondon em uma conferência dada à Sociedade Francesa de Filosofia 1960, quando afirma, em resposta a Gaston Berger, que não se trata de um objetivismo, neste "nós nos fazemos do objeto uma idéia pobre e negativa, ele é o que não é o sujeito, um resíduo do conhecimento que tem o sujeito" (SIMONDON, 1960). Seu sistema quereria ser um "transobjetivismo" (SIMONDON, 1960), pois:

[...] o verdadeiro real não é 'objetivo'; ele deve ser apreendido para além desta noção reducionista. Antes de toda oposição entre o sujeito e o objeto pode existir um modo de ser anterior ao modo de sujeito e ao modo de objeto. A operação de tomada de forma pertenceria precisamente a este modo de ser. Segundo esta perspectiva, a consciência não deveria ser considerada através de um esquema adversativo de 'tudo ou nada', de sujeito ou de objeto, mas sim a partir de uma transconsciência mais primitiva. Também, eu não creio poder manter este dualismo opondo sujeito e objeto, mas ao contrário, dever considerá-lo como exprimindo o resultado de um processo de tomada de forma que é, neste caso, o processo de individuação. É a palavra ontogênese que resume a questão (SIMONDON, 1960, p. 765).

Na esteira deste modo pré-individual - ao mesmo tempo pré-vital e pré-físico - de ser, que subverte toda a problemática homem/ máquina ou homem/natureza ${ }^{2}$, nos interessa assinalar dois desdobramentos. O primeiro deles é que o objeto técnico devém suporte e símbolo, "modelo", de uma relação que Simondon irá chamar de transindividual (SIMONDON, 1958, p. 247):

[...] uma relação que não coloca os indivíduos em relação por meio de suas individualidades constituídas separando-os uns dos outros, nem por meio do que há de idêntico em todo sujeito humano, por exemplo as formas a priori da sensibilidade, mas por meio desta carga de realidade pré-individual, desta carga de natureza que é conservada com o ser individual, e que contém potenciais e virtualidade. $\mathrm{O}$ objeto que aparece da invenção técnica carrega consigo alguma coisa do ser que a produziu, exprime deste ser o que é o menos atado a um hic et nunc; se poderia dizer que existe natureza humana no objeto técnico, no sentido onde a palavra natureza poderia ser empregada para designar o que resta de original, de anterior mesmo à humanidade constituída no homem (SIMONDON, 1958, p.247-8).

Percebe-se que, se por um lado a noção de transindividual implica pensar as relações

2 Contra a perspectiva de uma antropologia essencialista "o objeto técnico é para Simondon natureza no homem - e não "natureza" humana ou essência do homem [...] é então, subvertendo a oposição natureza/técnica que Simondon entende aqui subverter a oposição natureza/humanidade" (BARTHÉLÉMY, 2009, p.82). 
inter-humanas por uma perspectiva de constante tomada de forma envolvendo os potenciais carregados pelos indivíduos técnicos ou não, por outro aponta para uma topologia que transgride as referências habituais de interior e exterior baseadas na perspectiva dos indivíduos constituídos, permitindo pensar regimes de individuação singulares que exprimem tempos e espaços diversos através dos encontros, os quais podem compor corpos mais ou menos amplos, mais ou menos abertos ao futuro em si. Isto desde que o ser não se resume ao indivíduo.

O segundo desdobramento que decorre do primeiro é o desenvolvimento de uma tecnoestética. Esta intuição é desenvolvida por Simondon em uma carta a Derrida, na qual o autor propõe que "um espectro contínuo liga a estética à técnica" (SIMONDON, 1998, p.257), e que problemáticas culturais, sensoriais, estéticas e mesmo "orgásticas" (SIMONDON, 1998) envolvidas na invenção de um objeto técnico são transmitidas aos usuários, promovendo um plano supra-individual e topológico de constituição da "aísthesis, a intuição perceptiva fundamental" (SIMONDON, 1998, p. 260), para além de qualquer finalismo utilitário.

\section{Para pensar um "onto-poder"}

Ultrapassando a oposição homem/máquina abre-se a possibilidade para pensarmos que os processos de individuação das formas de perceber e sentir, implicam toda uma gama de indivíduos - técnicos ou não - e seus "meios associados", suas realidades pré- individuais, não sendo bons ou maus por si sós. Estes processos estão entramados com formas de expressão de poder que precisam ser contemplados.

Pensando as estratégias do departamento de defesa americano na luta contra o terror, Brian Massumi (2008) nos oferece interessantes pistas de como a incidência do poder eco- nômico no cotidiano ${ }^{3}$ foi migrando do que se poderia chamar de "hard power", poder que age por embate corpo-a-corpo, oposição de forças, para um "soft power", ou seja, uma guerra epistemológica na qual se produzem, disseminam e filtram informações opiniões e crenças, tornando "pacotes de informações" (LAPOUJADE, 2010, p. 161) os próprios indivíduos. Acompanhando Massumi (2008) seguimos para um "território" ainda mais sutil e insidioso, dito "proto-epistemológico", onde um maquinismo que opera por signos que mobilizam o medo de um evento catastrófico - sempre pressentido e muitas vezes adiado - produz uma excitação da atenção, uma disposição para a ação a partir de uma percepção aguçada e sem objeto definido, um estado de prontidão, uma emoção complexa de isolamento, dívida e ameaça (MASSUMI, 1993, 2005). A sutileza da ação proto-epistemológica se dá nos intervalos dos eventos, como manipulação de signos perceptivos e afetos que estariam implicados no próprio engendramento da ação e do pensamento por vir, de forma que "controlando a percepção do inimigo", busca-se o controle da "situação total" (MASSUMI, 2008). Trata-se aqui de uma biopolítica, uma gestão da vida, mas não daquela re-animalizada,

30 próprio autor aponta a "proximidade processual absoluta" entre a guerra e o cotidiano: "No nível inferior onde as duas linhas de base [guerra e não-batalha] convergem, a guerra em escala macro - a batalha, o cerco, e a ocupação - se encontra em proximidade processual absoluta com a guerra em escala micro da vida civil, da vida cotidiana" (MASSUMI, 2008)

4 Guerra com forte aptidão para o controle como lembra Lapoujade ao dizer que "todo mundo pode saber a todo instante o que faço, o que consulto como site, o que compro; pode conhecer meus centros de interesse, meus gostos, minha situação bancária, minha vida conjugal, familiar etc. [...]. A hipótese nada tem de paranóica, porque não se trata de vigilância, mas de controle, isto é, de levantamento de informações. Cada um de nós se reduz a um pacote de informações. Pertencer ao seu computador é estar sob controle, não necessariamente policial, mas empresarial, comercial etc., que se exerce sobre as informações que constituem cada modo de existência." (LAPOUJADE, 2010, p. 161) 
através dos estados de exceção, da "vida nua" como quer Agamben (2010), ou de uma "vitalidade reduzida ao mínimo físico, em proximidade absoluta com a morte", mas sim de um "onto-poder" (MASSUMI, 2008), um poder que busca interferir nas condições do sentir e do pensar, convocando uma "atividade nua" (bare activity), agindo sobre a vida, a vida seduzida, "re-animada" (MASSUMI, 2008). Ressalte-se que todo este investimento para "guiar" a ontogênese perceptiva é feito em vista de uma teleologia, que busca suprimir a singularidade da ação em favor da monotonia de consumo dos mundos ofertados ${ }^{5}$.

As propostas de Berardi, Virilio, Massumi e Lapoujade nos convidam a pensar a vivacidade ou vitalidade como algo ao mesmo tempo incitado e capturado, palco de produção de formas do viver e de sofrimentos particulares. Procuraremos com Simondon e Winnicott elaborar um caminho que contemple a idéia de vivacidade.

\section{Por uma teoria da vivacidade}

$\mathrm{Na}$ conclusão de sua tese de doutoramento Gilbert Simondon (1989) se debruça sobre as consequências éticas de suas pesquisas sobre os processos de individuação, as quais implicam a existência de um plano transindividual do ser, plano paradoxal que, participando dos

5 Lazzarato chamou de "guerra estética" o choque entre mundos e subjetividades surgidas da atualização do sensível, o que dá uma dimensão forte para a ação do capitalismo no plano imaterial. Neste regime - capitalista contemporâneo criam-se não mais os objetos apenas, mas o próprio mundo em que existem. Onde consumir um objeto é pertencer a um mundo com sua maneira de viver, de comer, de ter um corpo, de se vestir, etc. As transformações incorporais - neste sistema - criando por sedução uma nova sensibilidade, que é mais um mandamento autoritário, do que uma apropriação singular. Esta última é sempre inédita, já a sedução multiplica o mundo com uma série de "possíveis" já disponíveis para consumo, tentando "envelopar" a virtualidade (LAZZARATO, 2004, p. 229-33). indivíduos, se prolonga para além dele ${ }^{6}$.

Simondon chamará de "ato louco" ou "ato não moral" (SIMONDON, 1989, p. 242-5), aquele que busca ser si mesmo, que se insere no devir mas não cumpre a defasagem que o permitiria participar de uma problemática maior que si mesmo, transindividual, o permitiria amplificar seu ser por espraiamento lateral, devir verdadeiramente. Simondon ainda propõe a existência de um ato "parasita" ou "imoral"

[...] aquele que destrói as significações dos atos que existiram ou que poderão ser chamados a existir e que, no lugar de se localizar em si mesmo como o ato não moral, introduz um esquema de confusão impedindo os outros atos de se estruturarem em rede (SIMONDON, 1989, p. 244).

Simondon propõe uma idéia de alienação do sujeito em relação ao que pode, fazendo lembrar Espinosa, ao dizer que:

[...] um devir que absorve e destrói as significações relacionais dos outros atos, que os conduz por falsas pistas de transdutividade, que aliena o sujeito em relação a si mesmo: é um ato parasita, um falso ato que tira sua aparência de significação de um encontro aleatório (SIMONDON, 1989, p. 244)

A perspectiva ética, na obra de Simondon, nos coloca frente ao plano processual (en-

6 "É, com efeito, em cada instante de auto-constituição que a relação entre o indivíduo e o transindividual se define como aquilo que ultrapassa o indivíduo ao prolongá-lo: o transindividual não é exterior ao indivíduo e, no entanto, se destaca deste em certa medida" (grifo do autor) (SIMONDON, 1989, p. 156).

7 Simondon estende sua análise do ato imoral para aquela do estetismo, ou seja, "unificação dos atos segundo certo estilo comum e não segundo seu poder de transdutividade. O estetismo é um parasita do devir moral; ele é criação de formas abstratas na existência do sujeito, e ilusão de unificação segundo suas formas abstratas. $O$ estetismo, que quer atos sempre novos, em certo sentido mente para si mesmo e devém uma iteração da novidade segundo a norma extrínseca da novidade." (SIMONDON, 1989, p. 244). 
tendido como invenção de fases e não como transformação cronológica contínua) e topológico envolvido no limite que distribui indivíduo e coletivo transidividual, ao mesmo tempo que no limite que engendra o biológico e o acontecimental, plano que pode nos encaminhar para uma idéia de vivacidade.

O indivíduo é instado a individuar-se para resolver - parcialmente em nova configuração metaestável - os conflitos perceptivos e os afetos experienciados. Esta individuação que diminuirá a tensão de incompatibilidade do sujeito consigo e com o mundo só pode ocorrer através da participação no plano transindividual, implicando o seu ser individuado e a carga de realidade pré-individual associada a si com a carga de "natureza" pré-individual dos outros indivíduos ${ }^{8}$. Entende-se que o transindividual é um coletivo que não se resume a um coletivo de indivíduos ou ao socius, e que também inventa uma topologia singular não podendo ser concebido como interior ou exterior ao indivíduo, mas como sendo verdadeiramente "transindividual" (SIMONDON, 1989, p. 157), desta maneira Simondon pode afirmar que "a individualidade psicológica aparece como sendo aquilo que se elabora ao elaborar a transindividualidade" (SIMONDON, 1989 , p. 157).

Para podermos pensar o que poderia ser a vivacidade para além do vivo é preciso nos determos um pouco na teoria simondoniana de individuação orgânica. O biológico se funda pelo surgimento de uma membrana polarizada, seletiva, que irá determinar, o que irá ficar no perímetro externo ou interno do ser,

\footnotetext{
8 "A latência da emoção, inadequação do sujeito consigo mesmo, incompatibilidade de sua carga de natureza com sua realidade individuada, indica ao sujeito que ele é mais que ser individuado, e que encerra em si a energia para uma individuação ulterior; mas esta individuação não pode se fazer no ser do sujeito, mas apenas através deste ser com os outros seres, como coletivo transindividual." (SIMONDON, 1989, p. 213).
}

"o vivo vive no limite de si mesmo, sobre seu limite" (SIMONDON, 1995, p. 224). A membrana inventa um mosaico de tempos e espaços pois, ao englobar outras estruturas, como as mitocôndrias, ou ao se invaginar, como é o caso da cavidade intestinal, promove a convivência de diversas topologias, "exterioridades anexadas" produzindo "diversos níveis de interioridade" (SIMONDON, 1995, p. 224). Quanto mais complexo o ser, mais dependente desta cooperação espaciotemporal já que, diferentemente dos indivíduos físicos, aqueles não podem prescindir de partes de seu ser para continuar existindo. Nos seres complexos:

[...] todo o conteúdo do espaço interior está topologicamente em contato com o conteúdo do espaço exterior sobre os limites do vivo; com efeito não há distância em topologia [...] todos os produtos da individuação passada estão presentes sem distância ou retardo (SIMONDON, 1995, p. 225).

Importa notar que toda topologia implica uma cronologia própria. Para a substância viva:

[...] estar no interior da membrana polarizada seletiva significa que esta substância foi apreendida no passado condensado. O fato que uma substância esteja no meio de exterioridade significa que esta substância pode advir, ser proposta à assimilação, lesar o indivíduo vivo: ela está por vir (SIMONDON, 1995, p. 226).

Quando a individuação do vivo não é suficiente para dar conta dos desafios problemáticos aos quais ele está exposto ocorre uma individuação com características muito particulares que é a psíquica e coletiva. Simondon irá afirmar que para ser rigoroso só existem indivíduos físicos e biológicos, e que o psíquico e coletivo seria uma amplificação do processo que deu origem ao vivo, amplificação que se dá pelo que chamou de individualização (SIMONDON, 1989, p. 133-4). A individualização é contínua e desdobra o vivo (o qual é ape- 
nas unidade psicossomática funcional e relacional) em pensamento e funções orgânicas, por uma "clivagem assimétrica" (SIMONDON, 1989). Esta separação é apenas parcial e não estabelece uma identidade ou um paralelismo entre o psíquico e o somático, sendo estes realidades complementares que se combinam. A personalidade, para o autor, "é o que mantém a coerência da individuação [do vivo] e do processo permanente de individualização [psíquica e coletiva]" (SIMONDON, 1989, p. 134), sendo a expressão de uma metaestabilidade que, participando ativamente da constituição do psíquico e coletivo, está inalienavelmente ancorada no vivo. A coerência vital/somatopsíquica é conquistada descontinuadamente, por crises, através dos acontecimentos da vida cotidiana, por um processo chamado de "personalização", o qual determina a singularidade do indivíduo. Esta singularidade é a integração na personalidade, em uma única situação, da sexualidade (individuação do vivo) e da história individual dos acontecimentos (individualização psíquica e coletiva) (SIMONDON, 1989, p. 129). Aqui apresenta-se um paradoxo, pois, como apontamos antes "a individualidade psicológica aparece como sendo o que se elabora ao elaborar a transindividualidade" ( SIMONDON, 1989, p. 157), ou seja, a formação da singularidade psíquica constitui o transindividual, ao mesmo tempo que depende dele para se resolver parcialmente, este último constituindo uma anterioridade àquela (SIMONDON, 1989, p. 195). O transindividual, com efeito, é descoberto e ao mesmo tempo criado, se auto-constituindo na superfície de relação entre a interioridade psicológica e a exterioridade coletiva de realidade pré-individual sustentada pelos outros indivíduos.

Simondon irá buscar em Nietzsche a inspiração para dizer que é através dos acontecimentos que promovem uma "solidão" (SIMONDON, 1989, p. 155), um colocar em xeque do papel funcional do indivíduo na sociedade, um desmonte da individualidade, uma "desindividuação provisória", que se dará uma re-estruturação da personalidade, o sentimento de ser "habitada" (BARTHÉLÉMY, 2008, p. 111). Este sentimento nos parece dizer respeito à invenção topológica de uma participação em um coletivo bem mais amplo do que os limites da subjetividade. Simondon destaca que "topologia e cronologia coincidem na individuação do vivo" e que "apenas ulteriormente e segundo as individuações psíquica e coletiva que a coincidência pode ser rompida", isto por que "topologia e cronologia não são formas a priori da sensibilidade, mas a dimensionalidade mesma do vivo se individuando" (SIMONDON, 1995, p. 226). Justamente neste ponto abre-se a possibilidade de pensar uma ética e uma clínica dos atos ligado à ontogenia, a qual implica devir e estruturação topológica. Citamos Simondon:

Apreender a ética em sua unidade exige que se acompanhe a ontogênese: a ética é o sentido da individuação, o sentido da sinergia de individuações sucessivas. É o sentido da transdutividade do devir, sentido segundo o qual em cada ato reside ao mesmo tempo o movimento para ir mais longe e o esquema que se integrará aos outros esquemas; é o sentido segundo o qual a interioridade de um ato tem um sentido na exterioridade. Postular que o sentido interior é também um sentido exterior, que não existem ilhas perdidas no devir, ou regiões eternamente fechadas sobre si mesmas, ou ainda autarquia absoluta do instante, é afirmar que cada gesto tem um sentido de informação e é simbólico em relação à vida inteira e ao conjunto das vidas. Existe ética na medida em que há informação, quer dizer, significação seguindo uma disparação de elementos dos seres, e assim, fazendo com que aquilo que é interior seja também exterior (SIMONDON, 1989, p. 242).

Em uma perspectiva cronológica, diríamos rizomática e multidimensional, os atos morais "constroem uma simultaneidade recíproca, 
uma rede que não se deixa reduzir pela unidimensionalidade do sucessivo" (SIMONDON, 1989 , p. 244), retomando o passado e evocando o futuro através da transindividualidade com outros atos.

O que se transmite através do ato ético "é a universalidade de uma problemática" (SIMONDON, 1989, p. 154), mais do que um conjunto formal de dados e significações, lembrando que:

[...] o presente do ser é sua problemática em vias de resolução [...]. O ser individuado não é a substância, mas o ser posto em questão, o ser através de uma problemática, dividido, reunido, levado nesta problemática que se põe através dele e o faz devir, como ele faz o devir (SIMONDON, 1989, p. 224).

A produção de sentido é mais uma disparação, a afirmação intensiva das diferenças, do que um partilhar de clichês sensoriais ${ }^{9}$. Estes últimos dando condição às relações hierárquicas de quem possui e que consome o conhecimento ou os signos de status, por exemplo.

Depois deste rápido passeio por algumas das ideias de Simondon podemos propor que a vivacidade não pode estar simplesmente localizada no processo de individuação biológica, mas que depende desta, desde que a psíquica é uma ampliação daquela. É no limite topológico estabelecido entre as ações do sujeito psicossomático e os atos morais (ou imorais) do coletivo transindividual, entre a personali-

\footnotetext{
9 Aprendemos com Deleuze que os clichês são esquivas sensório-motoras, esquemas particulares de natureza afetiva que nos protegem do que é sentido como demais: horrível demais, belo demais, e assim não percebemos a imagem inteira (DELEUZE, 2005, p.31). Definição que ganha estatura política quando o autor diz que os interesses econômicos, as crenças ideológicas, as exigências psicológicas fomentam o hábito perceptivo, a reprodução do dado (DELEUZE, 2005). É assim que ele pode responder à sua própria pergunta "Civilização da imagem? Na verdade uma civilização do clichê, na qual todos os poderes têm interesse em nos encobrir as imagens, não forçosamente em nos encobrir a mesma coisa, mas encobrir alguma coisa na imagem" (DELEUZE, 2005, p. 32).
}

dade e a personalização que se instalará, para nós, a potência da vivacidade. Simondon lembra que, ao contrário, o psíquico pode buscar uma reprodução de si mesmo, uma nova individuação, sem participação no coletivo, quer dizer, proceder atos loucos ou parasitas o que irá mergulhá-lo cada vez mais na sensação de angústia ${ }^{10}$, ou seja, na falência da conquista do transindividual.

A vivacidade do ser implicaria necessariamente a experiência de acontecimentos que promovessem uma desindividuação, a partir da qual ocorreria uma nova individualização amplificadora que, por espraiamento lateral, participaria de um campo problemático maior que si mesma, ou seja, fazendo acompanhar o plano afetivo subconsciente transindividual na individuação biológica. Para experimentar o sentimento de ser "habitada" a personalidade precisa inventar uma topologia que envolva o seu mosaico espaciotemporal biopsíquico com a transindividualidade afetiva, colocando-se em contato afetivo, sem retardo ou distância, com aquilo que para os demais indivíduos é também transindividual. Assim se retoma a imagem do início deste texto de uma superfície ativa discriminada entre corporal/ incorporal, eu/outro, subjetivo/objetivo, formal/informe, singular/geral, e a esta imagem se apõe a idéia de vivacidade.

\section{Uma extensão psicanalítica para a idéia de vivacidade}

Não separamos ética de clínica e assim nos permitimos estender as intuições teóricas de

\footnotetext{
10 Remetemos o leitor interessado ao texto de Igor Krtolica "The question of anxiety in Gilbert Simondon" (2009) sobre a angústia em Simondon, pois esta elaboração extrapola o escopo deste texto. Nos permitimos indicar ao leitor nosso próprio texto "O impensável na clínica: virtualidades nos encontros clínicos" (ARAGON, 2007), para um desdobramento do que chamamos "agonias impensáveis" e que utiliza algumas das referências utilizadas aqui.
} 
Simondon para o território da psicanálise, mais especificamente a obra de Donald Winnicott.

Winnicott propõe que o lactente desenvolve dois tipos de relacionamento com a mãe ao mesmo tempo, uma com a "mãe-ambiente" (WINNICOTT, 1983, p. 166), com a qual a comunicação é silenciosa, não-verbal (WINNICOTT, 1983, p. 174), uma "não-comunicação simples" (WINNICOTT, 1983, p. 167) e que depende de uma "inconsistência" materna, gerando o ambiente propício para que o mundo seja ao mesmo tempo criado e descoberto e para que seja possível "se sentir real" (WINNICOTT, 1983, p. 169). O outro tipo de relação seria com a "mãe-objeto", elemento destacado no qual prevalece sua consistência própria e com o qual a comunicação deve ser explícita.

Os relacionamentos e (não)comunicações significativas são silenciosas (WINNICOTT, 1983, p. 167) e mais, "é daí que se origina a comunicação [explícita e indireta]" ( WINNICOTT, 1983, p. 174), e que se constitui a sensação de vivacidade (WINNICOTT, 1983, p.173-4)

No texto "Sobre o direito à não comunicação das diferenças" Brian Massumi (2002) trabalha longamente sobre esta questão, da qual pinçaremos apenas um ponto que remete à "vivacidade relacional da in-formação" (MASSUMI, 2002, p. 36), comunicação que não se aplica à transmissão de conteúdos formais, mas:

[...] se endereça ao ritmo de passagem entre dimensões ontológicas (de um lado o informe ou o indeterminado, de outro o formalmente estabelecido ou o determinável) [...] ritmo da reciprocidade reprocessualização-reestruturação (MASSUMI, 2002, p. 35).

Nos parece que o plano paradoxal, poético e "silencioso" de invenção e descoberta da realidade, no limite "entre" o subjetivo e o objetivo, tão presente na obra winnicottiana (WINNICOTT, 1975), vivido através da tensão entre ambiente e objetificação, pode ser aproximado do topos transindividual onde são experimentadas as resoluções parciais da afetividade subconsciente que vimos trabalhando até o momento, com um ganho se pensarmos de forma dinâmica que os ritmos de formação topológica podem ser pensados como a mediação entre a continuidade vital e a descontinuidade acontecimental, dando origem ao ser como "centro de gravidade", mais ou menos relacionado à pré-individualidade transindividual ${ }^{11}$. Retiro a expressão do próprio Winnicott quando diz que: "[...] a unidade não é o indivíduo, mas sim uma estrutura ambiente-indivíduo. O centro de gravidade do ser não tem sua origem no indivíduo. Sua origem repousa na estrutura como um todo" (WINNICOTT apud ABRAM, 2000, p. 240), isto é, aproximando-o de uma forma do pensar simondoniana, num complexo sistema metaestável.

\section{Conclusão}

Concordamos com Berardi e Massumi quando afirmam que é o plano das sensações, de uma vida seduzida e "re-animada", o topos da batalha que está sendo travada hoje e que diz respeito diretamente às formas do viver e adoecer atuais.

Consideramos que desenvolver uma concepção de vivacidade nos permite avançar no pensamento de uma ética e uma clínica que contemplem os desafios existenciais aos quais estamos sendo confrontados. Isto por que neste conceito estão implicados a necessidade de se contemplar os acontecimentos que singularizam o sujeito, a necessidade de uma desindividuação parcial para propi-

11 Os leitores de Winnicott se recordarão da teoria do trauma em Winnicott que implica uma solução de continuidade do "continuar sendo" (going-on-being), o qual, no escopo deste trabalho poderia ser pensado como a conquista e sustentação da ressonância lateral, da dimensionalidade transindividual do ser, para além do subjetivo individual e do objetivamente atualizado em formas individuais. 
ciar novas individualizações que impliquem o transindividual e a participação em uma problemática mais ampla do que os limites de si mesmo através de uma "comunicação silenciosa" que dá sentido ao viver. Estes pontos insistem para a manutenção da singularidade de uma continuidade problemática através dos atos que resista à homogeneização das ações implicada na tentativa de "conduzir" a gênese das formas de perceber e sentir difundida de maneira hegemônica pela comunicação hoje.

\section{Referências}

ABRAM, J. A linguagem de Winnicott: dicionário das palavras e expressões utilizadas por Donald W. Winnicott. Trad. Marcelo G. da Silva. Rio de Janeiro: Revinter, 2000.

AGAMBEN, G. Homo Sacer: o poder soberano e a vida nua I. Trad. Henrique Burigo. Belo Horizonte: Editora UFMG, 2010.

ARAGON, L. E. P. O impensável na clínica: virtualidades nos encontros clínicos. Coleção Cartografias. Porto Alegre: Sulina/Editora da UFRGS, 2007.

BARTHÉLÉMY, J-H. Simondon ou I'encyclopédisme genetique. Paris, France: PUF, 2008.

BARTHÉLÉMY, J-H. Du mort qui saisit Le vif. Sur l'actualité de I'ontologie simondonienne. In: Cahiers Simondon Numéro1. Paris: L’Harmattan, 2009.

BERARDI, F. I will be brief. Disponível em: http://th-rough.eu/writers/bifo-eng/i-will-be-brief , 2010, (acesso em 10/06/2011).

BERARDI, F. A sensibilidade é hoje o campo de batalha político. Disponível em: http://bocadomangue. wordpress.com/2011/01/30/"a-sensibilidade-e-hoje-o-campo-de-batalha-politico"/, 2011 (acesso em 10/06/2011).

DELEUZE, G. A imagem-tempo. Trad. Eloisa A Ribeiro. São Paulo: Brasiliense, 2005.

KRTOLICA, I. The Question of anxiety in Gilbert Simondon. Disponível em: http://www.parrhesiajournal. org/parrhesia07/parrhesia07_krtolica.pdf, 2009 (acesso em 10/06/2011).

LAPOUJADE, D. Deleuze: política e informação. In: Cadernos de Subjetividade (publicação anual do Núcleo de Estudos e Pesquisas da Subjetividade do Programa de Psicologia Clínica da PUC-SP). Trad. Luiz B. L. Orlandi, 2010.

LAZZARATO, M. Creer des mondes: capitalisme contemporain et guerres "esthétiques". Multitudes. N. 15, Hiver, pp. 229-237, 2004. 
MASSUMI, B. Everywhere you want to be. Disponível em:

http://www.brianmassumi.com/textes/EVERYWHERE\%20YOU\%20WANT\%20TO\%20BE.pdf, 1993 (acesso em 06/06/2011).

MASSUMI, B. Sur le droit à la non-communication de la differénce. Disponível em: http://www.brianmassumi.com/textes/Droit\%20a\%20la\%20non-communication.pdf, 2002 (acesso em 06/06/2011).

MASSUMI, B. Perception attack: note sur un temps de guerre. Disponível em: http://www.cairn.info/revue-multitudes-2008-3-page-74.htm, 2008 (acessado em 06/06/2011).

SIMONDON, G. Forma, informação e potenciais. In: Bulletin de La Société française de philosophie, séance de 27 février 1960 .

SIMONDON, G. L'Individuation psychique et collective: à la lumière des notions de forme, information, potenciel et métastabilité. Paris: Aubier, 1989.

SIMONDON, G. L'individu et sa gênese physico-biologique. Grenoble, France: Jérôme Millon, 1995.

SIMONDON, G. Sobre a tecno-estética: Carta a Jacques Derrida. In: Tendência e Cultura: ensaios sobre o tempo presente. Hermetes R. de Araújo (Org.). Trad. Stella Senra. São Paulo: Estação Liberdade, 1998.

VIRILIO, P. Dromologie : logique de La course. Disponível em: http://multitudes.samizdat.net/Dromologie-logique-de-la-course, 1991 (acesso em 06/06/2011). VIRILIO, P. Velocidade de Libertação. Lisboa, Portugal: Relógio D’Água, 2000.

WINNICOTT, D. W. O brincar e a realidade. Trad. José O. A Abreu e Vanede Nobre. Rio de Janeiro: Imago, 1975.

WINNICOTT, D. W. O ambiente e os processos de maturação: estudos sobre a teoria do desenvolvimento emocional. Trad. Irineo C S Ortiz. Porto Alegre: Artmed, 1983.

Recebido em: 12 de junho de 2011

Aprovado para publicação em: 06 de outubro de 2011

\section{Luis Eduardo Ponciano Aragon}

Médico cardiologista, Psicanalista, Mestre em Cardiologia (UNIFESP) e Doutor em Psicologia Clínica (PUC-SP), São Paulo/SP, Brasil. E-mail: aragonn@uol.com.br 